\title{
Quinoline-2-carboxylic Acid Isolated from Ephedra pachyclada and Its Structural Derivatives Show Inhibitory Effects against $\alpha$-Glucosidase and $\alpha$-Amylase
}

\author{
Hwa-Won Lee $\cdot$ Ji-Yeon Yang $\cdot$ Hoi-Seon Lee
}

Received: 13 May 2014 / Accepted: 5 June 2014 / Published Online: 31 August 2014

(C) The Korean Society for Applied Biological Chemistry and Springer 2014

\begin{abstract}
The aim of present study was to isolate a bioactive compound from the chloroform fraction of Ephedra pachyclada stems and to evaluate antidiabetic activities against $\alpha$-glucosidase and $\alpha$-amylase. According to various chromatographic and spectroscopic analyses, the bioactive compound of $E$. pachyclada was identified as quinoline-2-carboxylic acid. Based on the $\mathrm{IC}_{50}$ values of quinoline-2-carboxylic acid derivatives against $\alpha$ glucosidase and $\alpha$-amylase, quinoline-2-carboxylic acid (9.1 and $15.5 \mu \mathrm{g} / \mathrm{mL}$ ) exhibited potent inhibitory activities, followed by quinoline-3-carboxylic acid (10.6 and $31.4 \mu \mathrm{g} / \mathrm{mL})$, quinoline-4carboxylic acid $(60.2$ and $152.4 \mu \mathrm{g} / \mathrm{mL})$, and acarbose (66.5 and $180.6 \mu \mathrm{g} / \mathrm{mL}$ ) against $\alpha$-glucosidase and $\alpha$-amylase, respectively. However, quinoline-2-carboxaldehyde, quinoline-3-carboxaldehyde, and quinoline-4-carboxaldehyde showed no inhibitory activities. Antidiabetic activity depended on the existence of a carboxyl group on quinoline for activities against $\alpha$-glucosidase and $\alpha$ amylase. Therefore, E. pachyclada and quinoline-2-carboxylic acid derivatives could be suitable as alternative synthetic antidiabetic agents.
\end{abstract}

Keywords antidiabetic activity $\cdot$ Ephedra pachyclada $\cdot$ quinoline2 -carboxylic acid $\cdot \alpha$-amylase $\cdot \alpha$-glucosidase

\section{Introduction}

Diabetes mellitus is a common metabolic disease characterized by hyperglycemic syndrome that causes many complications such as cardiovascular disease, diabetic neuropathy, and diabetic retinopathy

H.-W. Lee $\cdot$ J.-Y. Yang $(\bowtie) \cdot$ H.-S. Lee $(\bowtie)$

Department of Bioenvironmental Chemistry and Institute of Agricultural Science \& Technology, College of Agriculture \& Life Science, Chonbuk National University, Jeonju 561-756, Republic of Korea

E-mail: hoiseon@jbnu.ac.kr; jiyeo0527@jbnu.ac.kr
(Choi et al., 2008). Hydrolysis of starch is a major process for blood glucose regulation, and $\alpha$-amylase and $\alpha$-glucosidase are the key enzymes related to intestinal absorption and starch breakdown, respectively (Wang et al., 2010). Inhibiting key enzymes can significantly decrease blood glucose level after a mixed carbohydrate diet (Lee, 2005; Wang et al., 2010). Therefore, the regulation of blood glucose by $\alpha$-amylase and $\alpha$-glucosidase can be an important strategy for managing hyperglycemia linked to type II diabetes (Lee, 2005; Wang et al., 2010). Chemical inhibitors are widely used for clinical treatment, such as acarbose and glimepiride (Cha et al., 2009). However, these inhibitors cause side effects such as abdominal cramping, diarrhea, and flatulence (Cha et al., 2009; Jeong et al., 2012).

Plant-derived materials had been used as alternative materials due to their bioactive substances (Lee and Ahn, 1998; Lee, 2002; Yang et al., 2002; Yang et al., 2003). In addition, previous studies have reported that natural products possess $\alpha$-amylase and $\alpha$ glucosidase inhibitory effects (Kim et al., 2009). Ephedra pachyclada (Ephedraceae) is one of approximately 50 Ephedra species worldwide and has been used as a traditional medicine for a long time (Marzieh et al., 2014). In particular, E. pachyclada stems have been widely used (Caveney et al., 2001; Marzieh et al., 2014). Although diverse bio-functional activities of E. pachyclada stems have been reported, few studies have reported the antidiabetic activity of E. pachyclada stems and its bioactive compound. Thus, this study was conducted to isolate a bioactive compound from $E$. pachyclada stems and determine the antidiabetic activities of $E$. pachyclada stems, the isolated compound, as well as its structural derivatives against $\alpha$-amylase and $\alpha$-glucosidase.

\section{Materials and Methods}

Chemicals. The chemicals used were acarbose, quinoline-3carboxylic acid, quinoline-4-carboxylic acid, quinoline-2- 
carboxyaldehyde, quinoline-3-carboxyaldehyde, and quinoline-4carboxyaldehyde (Sigma-Aldrich, USA). All chemicals were of reagent grade.

Materials. E. pachyclada stems $(5 \mathrm{~kg})$ were supplied from a traditional market (Korea). The E. pachyclada stems were cut into pieces, powdered, extracted twice with methanol $(25 \mathrm{~L})$ at room temperature for 2 days, and filtered using filter paper. The filtrate was vacuum-concentrated at $45^{\circ} \mathrm{C}$ using a rotary vacuum evaporator (EYELA, Japan), and the yield of the methanol extract from $E$. pachyclada stems was $25.5 \%$. Subsequently, the methanol extract $(20 \mathrm{~g})$ of E. pachyclada stems was continually partitioned into hexane, chloroform, ethyl acetate, $n$-butyl alcohol, and water fractions. The organic fractions were concentrated using a rotary vacuum evaporator at $45^{\circ} \mathrm{C}$, whereas the water fraction was freeze-dried.

Isolation and identification. The chloroform (10 g) fraction was loaded onto a silica gel column (70-230 mesh, Merck, Germany, $600 \mathrm{~mm}$ i.d. $\times 750 \mathrm{~mm}$ ) and sequentially eluted with hexane and mixtures of chloroform: methylene chloride (10:1, 7:3, 5:1, and $1: 1, \mathrm{v}: \mathrm{v})$, resulting in six fractions (P1-P6), respectively. All fractions were analyzed by thin layer chromatography (chloroform: methylene chloride, 7:3, v:v). Similar fractions were combined and bioassayed. The P3 fraction exhibited $\alpha$-amylase and $\alpha$ glucosidase inhibitory activities; therefore, this fraction was chromatographed on a silica gel column $(400 \mathrm{~mm}$ i.d. $\times 800 \mathrm{~mm})$ using chloroform:methylene chloride $(7: 3, \mathrm{v}: \mathrm{v})$ to obtain the active P32 fraction. The P32 fraction was isolated by preparative high-performance liquid chromatography (HPLC) (Japan Analytical Industry Co., Ltd., Japan) and was applied to a JAI gel GS Series column (JAI GS310 $300 \mathrm{~mm} \times 2+$ JAI GS310 $500 \mathrm{~mm}$ ) with a mixture of chloroform:methylene chloride $(7: 3, \mathrm{v}: \mathrm{v})$ at a flow rate of $5.0 \mathrm{~mL} / \mathrm{min}$ as the mobile phase. The active P321 fraction was re-chromatographed using a JAI gel W series column (W253 500 $\mathrm{mm}+\mathrm{W} 252500 \mathrm{~mm}$ ) with a mixture of chloroform:methylene chloride (7:3, v:v) under the same conditions. Finally, the P3212 fraction $(215 \mathrm{mg})$ was isolated. The structure of the P3212 fraction was determined by spectroscopic analyses. ${ }^{1} \mathrm{H}$ - and ${ }^{13} \mathrm{C}$ NMR spectra were obtained using a JNM-ECA600 spectrometer (JEOL Ltd, Japan; ${ }^{1} \mathrm{H}-600 \mathrm{MHz} ;{ }^{13} \mathrm{C}-150 \mathrm{MHz}$ ) with $\mathrm{CDCl}_{3}$.

Antidiabetic activity. The antidiabetic effects of E. pachyclada, the isolated compound, and its structural derivatives were assessed against $\alpha$-amylase and $\alpha$-glucosidase. $\alpha$-amylase inhibitory activity was assayed according to the procedure described by Wang et al. (2010) with some modifications. The enzyme solution (6.25 U/ $\mathrm{mL}$ ) was prepared by dissolving $\alpha$-amylase (Sigma Co., USA) in $0.5 \mathrm{M}$ Tris-HCl buffer ( $\mathrm{pH}$ 6.9). Starch azure $(8 \mathrm{mg}$ ) was suspended in $0.5 \mathrm{M}$ Tris- $\mathrm{HCl}$ buffer containing $0.01 \mathrm{M}$ calcium chloride and soaked in boiling water for $5 \mathrm{~min}$, followed by preincubation at $37^{\circ} \mathrm{C}$ for $10 \mathrm{~min}$. The enzyme solution $(100 \mu \mathrm{L})$ and sample $(100$ $\mu \mathrm{L})$ in $50 \%$ dimethyl sulfoxide were mixed in a $96-$ well plate. After $10 \mathrm{~min}, 50 \%$ acetic acid $(50 \mu \mathrm{L})$ was added to stop the reaction. The absorbance of the reactants was measured at $595 \mathrm{~nm}$ with a microplate reader (Model ASYS UVM 340, Biochrom
Ltd., UK). Acarbose was employed as the positive control. All tests were replicated three times. Percent (\%) inhibition was determined using the following equation: Inhibition $(\%)=[1$ (sample/control)] $\times 100 . \mathrm{IC}_{50}$ values were calculated by applying logarithmic regression analysis. $\alpha$-Glucosidase inhibitory activity was assayed according to the procedure described by Shinde et al. (2008) with a slight modification. The formation of $p$-nitrophenol was measured using $\alpha$-glucosidase after a reaction with $p$ nitrophenyl- $\alpha$-D-glucopyranoside (NPG). The enzyme solution $(0.6 \mathrm{U})$ was prepared by dissolving $\alpha$-glucosidase in $0.1 \mathrm{M}$ phosphate buffer ( $\mathrm{pH} 7.0$ ) containing $2 \mathrm{~g} / \mathrm{L}$ bovine serum albumin and $0.2 \mathrm{~g} / \mathrm{L}$ sodium azide. The enzyme solution $(50 \mu \mathrm{L})$ and sample $(10 \mu \mathrm{L})$, dissolved in dimethyl sulfoxide, were mixed and placed in a 96-well plate. After $15 \mathrm{~min}, 5 \mathrm{mM} \mathrm{NPG}(50 \mu \mathrm{L})$ in the same buffer was added, and the mixture was incubated for $10 \mathrm{~min}$ at $37^{\circ} \mathrm{C}$. Sodium carbonate $(0.1 \mathrm{M})$ was subsequently added to stop the reaction. Absorbance of the reactants was measured at $405 \mathrm{~nm}$ using a microplate reader (Model ASYS UVM 340, Biochrom Ltd.). Acarbose was employed as the positive control. All tests were replicated three times. Percentage (\%) inhibition was determined using the following equation: Inhibition $(\%)=[1$ (sample/control) $] \times 100$. The $\mathrm{IC}_{50}$ values were calculated by applying logarithmic regression analysis.

\section{Results and Discussion}

The active compound of the chloroform fraction from E. pachyclada stems was isolated by silica gel column chromatography and prep HPLC, and the structure of the isolated compound was determined by various spectroscopic analyses including EI-MS, ${ }^{1} \mathrm{H}-\mathrm{NMR}$, and ${ }^{13} \mathrm{C}-\mathrm{NMR}$ and by direct comparison with an authentic standard compound. The active compound was identified as quinoline-2carboxylic acid (Fig. 1) based on the following: quinoline-2carboxylic acid $\left(\mathrm{C}_{10} \mathrm{H}_{7} \mathrm{NO}_{2}\right.$, MW: 173); EI-MS (70 eV) $\mathrm{m} / z 173$ $\left[\mathrm{M}^{+}\right]$; ${ }^{1} \mathrm{H}-\mathrm{NMR}\left(600 \mathrm{MHz}, \mathrm{CD}_{3} \mathrm{OD}\right) \delta_{\mathrm{H}} 10.82(\mathrm{H}, \mathrm{dd}, J=6.37 \mathrm{~Hz}$, H-7), 8.56 (H, d, $J=6.82 \mathrm{~Hz}, \mathrm{H}-2), 7.87(3 \mathrm{H}, \mathrm{d}, J=6.02 \mathrm{~Hz}, \mathrm{H}-$ 1, 3, 6), $7.75(\mathrm{H}, \mathrm{d}, J=6.21 \mathrm{~Hz}, \mathrm{H}-5), 7.41(\mathrm{H}, \mathrm{d}, J=6.98 \mathrm{~Hz}, \mathrm{H}-$ 4); ${ }^{13} \mathrm{C}-\mathrm{NMR}\left(150 \mathrm{MHz}, \mathrm{CD}_{3} \mathrm{OD}\right) \delta_{\mathrm{C}} 167.3(\mathrm{C}-11), 149.2(\mathrm{C}-2)$, 148.5 (C-10), 136.1 (C-4), 130.4 (C-8), 129.5 (C-5, C-9), 128.2 (C-8), 126.9 (C-6), 121.2 (C-3). The ${ }^{1} \mathrm{H}-\mathrm{NMR}$ and ${ }^{13} \mathrm{C}-\mathrm{NMR}$ spectra of P3212 matched with those of quinoline-2-carboxylic acid isolated from Ephedra species (Starratt and Caveney, 1996; Lee and Lee, 2009).

The antidiabetic activities of quinoline-2-carboxylic acid, and its structural derivatives, including quinoline-3-carboxylic acid, quinoline-4-carboxylic acid, quinoline-2-carboxaldehyde, quinoline3-carboxaldehyde, and quinoline-4-carboxaldehyde, as well as acarbose as a positive control were evaluated against $\alpha$-amylase and $\alpha$-glucosidase. Based on the $\mathrm{IC}_{50}$ values of quinoline-2carboxylic acid, its structural derivatives, and acarbose against $\alpha$ amylase, quinoline-2-carboxylic acid $(15.5 \pm 1.9 \mu \mathrm{g} / \mathrm{mL})$ had the most potent antidiabetic activity, followed by quinoline-3-carboxylic 
(A)<smiles>O=C(O)c1ccc2ccccc2n1</smiles>

(D)<smiles>O=Cc1ccc2ccccc2n1</smiles>

(B)<smiles>O=C(O)c1cnc2ccccc2c1</smiles>

(E)<smiles>O=Cc1cnc2ccccc2c1</smiles>

(C)<smiles>O=C(O)c1ccnc2ccccc12</smiles>

(F)<smiles>O=Cc1ccnc2ccccc12</smiles>

Fig. 1 Structures of quinoline-2-carboxylic acid derivatives: (A) Quinoline-2-carboxylic acid; (B) quinoline-3-carboxylic acid; (C) quinoline-4carboxylic acid; (D) quinoline-2-carboxyaldehyde; (E) quinoline-3-carboxyaldehyde; (F) quinoline-4-carboxyaldehyde.

acid $(31.4 \pm 2.2 \mu \mathrm{g} / \mathrm{mL})$, quinoline-4-carboxylic acid $(152.4 \pm 2.5$ $\mu \mathrm{g} / \mathrm{mL})$, and acarbose $(180.6 \pm 1.3 \mu \mathrm{g} / \mathrm{mL})$. Quinoline-2-carboxylic acid $(9.1 \pm 2.3 \mu \mathrm{g} / \mathrm{mL})$ had the strongest antidiabetic activity in the case of $\alpha$-glucosidase inhibitory activities of quinoline-2-carboxylic acid and its structural derivatives, followed by quinoline-3carboxylic acid $(10.6 \pm 1.4 \mu \mathrm{g} / \mathrm{mL})$, quinoline-4-carboxylic acid $(60.2 \pm 2.1 \mu \mathrm{g} / \mathrm{mL})$, and acarbose $(66.5 \pm 1.5 \mu \mathrm{g} / \mathrm{mL})$. However, quinoline-2-carboxaldehyde, quinoline-3-carboxaldehyde, and quinoline-4-carboxaldehyde had no activity against $\alpha$-amylase and $\alpha$-glucosidase (Table 1). These results indicate that quinoline2-carboxylic acid and its structural derivatives isolated from $E$. pachyclada stems have excellent inhibitory effects against $\alpha$ amylase and $\alpha$-glucosidase. Similarly, Chohachi et al. (1985) reported that $E$. distachya and an isolated compound had hypoglycemic activity. In addition, the antidiabetic activities of

Table 1 Antidiabetic activities of quinoline-2-carboxylic acid derivatives and acarbose against $\alpha$-glucosidase and $\alpha$-amylase

\begin{tabular}{ccc}
\hline \multirow{2}{*}{ Samples } & \multicolumn{2}{c}{ Antidiabetic activity } \\
\cline { 2 - 3 } & $\begin{array}{c}\alpha \text {-glucosidase } \\
\text { inhibition IC } \\
\left.(\mu \mathrm{g} / \mathrm{mL})^{\mathrm{a}}\right)\end{array}$ & $\begin{array}{c}\alpha \text {-amylase } \\
\text { inhibition IC } \\
(\mu \mathrm{g} / \mathrm{mL})\end{array}$ \\
\hline Quinoline-2-carboxylic acid & $9.1 \pm 2.3$ & $15.5 \pm 1.9$ \\
Quinoline-3-carboxylic acid & $10.6 \pm 1.4$ & $31.4 \pm 2.2$ \\
Quinoline-4-carboxylic acid & $60.2 \pm 2.1$ & $152.4 \pm 2.5$ \\
Quinoline-2-carboxaldehyde & $\mathrm{NI}$ & $\mathrm{NI}$ \\
Quinoline-3-carboxaldehyde & $\mathrm{NI}$ & $\mathrm{NI}$ \\
Quinoline-4-carboxaldehyde & $\mathrm{NI}$ & $\mathrm{NI}$ \\
Acarbose $^{\mathrm{c})}$ & $66.5 \pm 1.5$ & $180.6 \pm 1.3$ \\
\hline
\end{tabular}

${ }^{\mathrm{a}} \mathrm{IC}_{50}$ values calculated from regression lines, using five different concentrations in triplicate experiments.

b) Acarbose was used as a positive control.

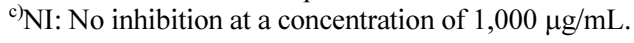

quinoline-2-carboxylic acid, quinoline-3-carboxylic acid, and quinoline-4-carboxylic acid, which contain a carboxyl group on quinoline, were more active against $\alpha$-amylase and $\alpha$-glucosidase than those of quinoline-2-carboxaldehyde, quinoline-3-carboxaldehyde, and quinoline-4-carboxaldehyde, with an aldehyde group on quinoline. In this regard, quinoline-2-carboxylic acid isolated from E. pachyclada stems and its structural derivatives (including a carboxyl group) could regulate the function of $\alpha$-amylase and $\alpha$ glucosidase. Matsuda et al. (1998) reported that the existence of a carboxyl group affected the antidiabetic effect. Our findings indicate that E. pachyclada and quinoline-2-carboxylic acid derivatives could be suitable as alternative synthetic antidiabetic agents.

\section{References}

Caveney S, Charlet DA, Freitag H, Maier-Stolte M, and Starratt AN (2001) New observations on the secondary chemistry of world Ephedra (Ephedraceae). Am J Bot 88, 1199-208.

Cha MR, Park JH, Choi YH, Choi CW, Hong KS, Choi SU et al. (2009) Alpha-glucosidase inhibitors from the branches extract of Cotinus coggygria. Kor J Pharmacogn 40, 229-32.

Chohachi K, Takakazu M, and Hiroshi H (1985) Isolation and hypoglycemic activity of ephedrans A, B, C, D and E, glycans of Ephedra distachya herbs. Planta Med 51, 162-3.

Choi HJ, Jeong YK, Kang DO, and Joo WH (2008) Inhibitory effects of four solvent fractions of Alnus firma on $\alpha$-amylase and $\alpha$-glucosidase. $J$ Life Sci 18, 1005-10.

Jeong EY, Cho KS, and Lee HS (2012) $\alpha$-Amylase and $\alpha$-glucosidase inhibitors isolated from Triticum aestivum L. Sprouts. J Korean Soc Appl Biol Chem 55, 4751.

Kim GN, Shin JG, and Jang HD (2009) Antioxidant and antidiabetic activity of Dangyuja (Citrus grandis Osbeck) extract treated with Aspergillus saitoi. Food Chem 117, 35-41.

Lee $\mathrm{CH}$ and Lee HS (2009) Growth inhibiting activity of quinaldic acid isolated from Ephedra pachyclada against intestinal bacteria. J Korean 
Soc Appl Biol Chem 52, 331-5.

Lee HS (2002) Tyrosinase inhibitors of Pulsatilla cernua root-derived materials. J Agric Food Chem 50, 1400-3.

Lee HS (2005) Cuminaldehyde: aldose reductase and $\alpha$-glucosidase inhibitor derived from Cuminum cyminum L. seeds. J Agric Food Chem 53, 2446-50.

Lee HS and Ahn YJ (1998) Growth-inhibiting effects of cinnamomum cassia bark-derived materials on human intestinal bacteria. J Agric Food Chem 46, 8-12.

Marzieh G, Mahnaz A, Mansoor J, Ghadireh M, Shahram N, Mohammad M et al. (2014) Protective effects of Ephedra pachyclada extract on mouse models of carbon tetrachloride-induced chronic and acute liver failure. Tissue Cell 46, 78-85.

Matsuda H, Li Y, Murakami T, Matsumura N, Yamahara J, and Yoshikawa M (1998) Antidiabetic principles of natural medicines. III. Structure-related inhibitory activity and action mode of oleanolic acid glycosides on hypoglycemic activity. Europe pubmed central 46, 1399-403.

Shinde J, Taldone T, Barietta M, Kunaparaju N, Hu B, and Kumar S (2008) $\alpha$-Glucosidase inhibitory activity of Syzygium cumini (Linn.) skeels seed kernel in vitro and in goto-kakizake (GK) rats. Carbohydr Res 343, $1278-81$.

Starratt AN and Caveney S (1996) Quinoline-2-carboxylic acid from Ephedra species. Phytochemistry 42, 1477-8.

Wang H, Du YJ, and Song HC (2010) $\alpha$-Glucosidase and $\alpha$-amylase inhibitory activities of guava leaves. Food Chem 123, 6-13.

Yang YC, Lee SG, Lee HK, Kim MK, Lee SH, and Lee HS (2002) A piperidine amide extracted from Piper longum L. fruit shows activity against Aedes aegypti mosquito larvae. J Agric Food Chem 50, 3765-7.

Yang YC, Lim MY, and Lee HS (2003) Emodin isolated from Cassia obtusifolia (Leguminosae) seed shows larvicidal activity against three mosquito species. J Agric Food Chem 51, 7629-31. 